Case Report

\title{
Heart Transplantation in a 14-Year-Old Boy in the Presence of Severe Out-of-Proportion Pulmonary Hypertension due to Restrictive Left Heart Disease: A Case Report
}

\author{
Martin Schwienbacher, ${ }^{1}$ Ulrich Schweigmann, ${ }^{1}$ Nikolaus Neu, ${ }^{2}$ Elisabeth Schermer, \\ Corinna Velik-Salchner, ${ }^{3}$ Ina Michel-Behnke, ${ }^{4}$ \\ Erentraud Irnberger, ${ }^{5}$ Christina Maria Steger, ${ }^{6}$ Jörg Ingolf Stein, ${ }^{1}$ and Ralf Geiger ${ }^{1}$ \\ ${ }^{1}$ Department of Pediatrics, Division of Cardiology, Pulmology, Allergology and Cystic Fibrosis, Innsbruck Medical University, \\ 6020 Innsbruck, Austria \\ ${ }^{2}$ Department of Pediatrics, Pediatric Intensive Care Unit, Innsbruck Medical University, 6020 Innsbruck, Austria \\ ${ }^{3}$ Department of Anaesthesiology and Critical Care Medicine, Innsbruck Medical University, 6020 Innsbruck, Austria \\ ${ }^{4}$ Department of Pediatric Cardiology, Medical University of Vienna, 1090 Vienna, Austria \\ ${ }^{5}$ Department of Pediatrics, Salzburg State Hospital, 5020 Salzburg, Austria \\ ${ }^{6}$ Department of Pathology, Innsbruck Medical University, 6020 Innsbruck, Austria
}

Correspondence should be addressed to Martin Schwienbacher; martin.schwienbacher@i-med.ac.at

Received 28 February 2013; Accepted 25 March 2013

Academic Editors: C. D. Barrett and A. Movahed

Copyright (C) 2013 Martin Schwienbacher et al. This is an open access article distributed under the Creative Commons Attribution License, which permits unrestricted use, distribution, and reproduction in any medium, provided the original work is properly cited.

\begin{abstract}
A 14-year-old boy after balloon valvuloplasty of severe aortic valve stenosis in the neonatal period was referred for heart-lung transplantation because of high grade pulmonary hypertension and left heart dysfunction due to endocardial fibroelastosis with severe mitral insufficiency. After heart catheterization, hemodynamic parameters were invasively monitored: a course of levosimendan and initiation of diuretics led to a decrease of pulmonary capillary wedge pressure (from maximum 35 to $24 \mathrm{mmHg}$ ). Instead of an expected decrease, mean pulmonary artery pressures (mPAP) increased up to $80 \mathrm{mmHg}$ with increasing transpulmonary pressure gradient (TPG) up to $55 \mathrm{mmHg}$. Oral bosentan and intravenous epoprostenol then led to a 50\% decrease of mPAP (TPG between 16 and $22 \mathrm{mmHg}$ ). The boy was listed solely for heart transplantation which was successfully accomplished 1 month later.
\end{abstract}

\section{Case}

A 14-year-old boy presented with the history of severe aortic valve stenosis; he had undergone successful balloon valvuloplasty at the age of 3 days. He was on followup elsewhere and was reportedly in stable clinical condition for 13 years, performing alpine skiing, cross country running, and mountain biking. He reportedly had normal systolic left heart function in the presence of left ventricular endocardial fibroelastosis (EFE) without signs of elevated right ventricular pressure on echocardiography. Neither heart catheterization nor cardiopulmonary exercise testing was performed. At the age of 14 years, he complained of fatigue during cycling and hiking for the first time. On echocardiography at that time severe mitral valve regurgitation and a markedly enlarged left atrium were seen besides the well-known mild aortic valve stenosis/regurgitation and endocardial fibroelastosis. Tricuspid valve regurgitation was demonstrated with a maximum velocity of $5.28 \mathrm{~m} / \mathrm{sec}$ presuming a systolic pulmonary artery pressure of $111 \mathrm{mmHg}$ (Figure 1).

The boy was scheduled for heart catheterization. On admission, he was physically still active but had stopped sports. On physical examination, he was eupneic with a heart rate of 79 beats per minute at rest, blood pressure was $100 / 60 \mathrm{mmHg}$, and transcutaneous oxygen saturation $\left(\mathrm{SaO}_{2}\right)$ was $97 \%$. He had a 3/6 systolic heart murmur with punctum maximum over the third intercostal space at the left and 


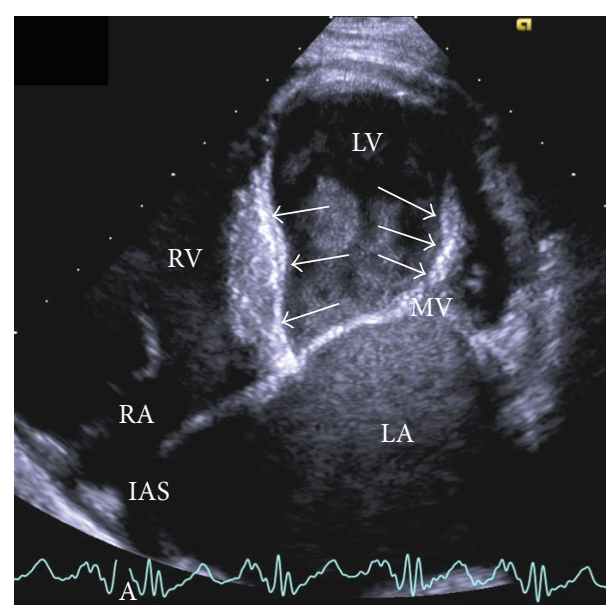

(a)

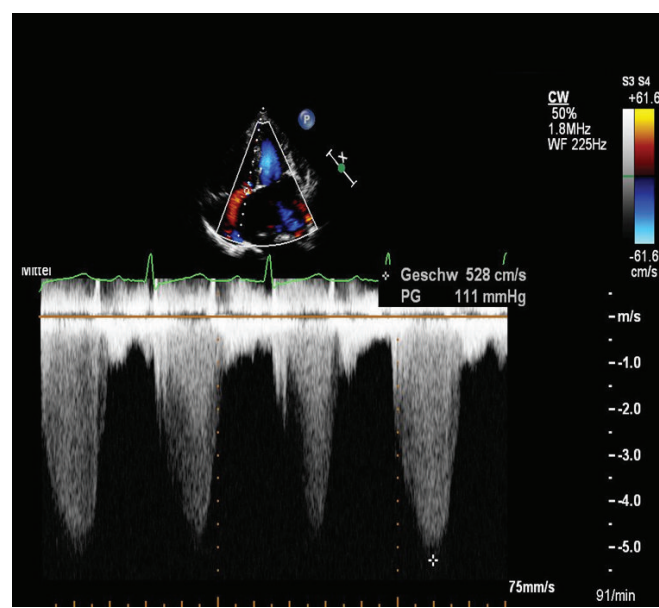

(b)

FIGURE 1: Echocardiography: 4-chamber view showing extremely enlarged left atrium (LA) and endocardial fibroelastosis (arrows) of left ventricle (LV) and mitral valve apparatus (a). Doppler maximum velocity of tricuspid insufficiency before initiation of medical therapy, indicating high systolic RV pressure of $111 \mathrm{mmHg}(\mathrm{b})$. RV = right ventricle; RA = right atrium; IAS = interatrial septum.

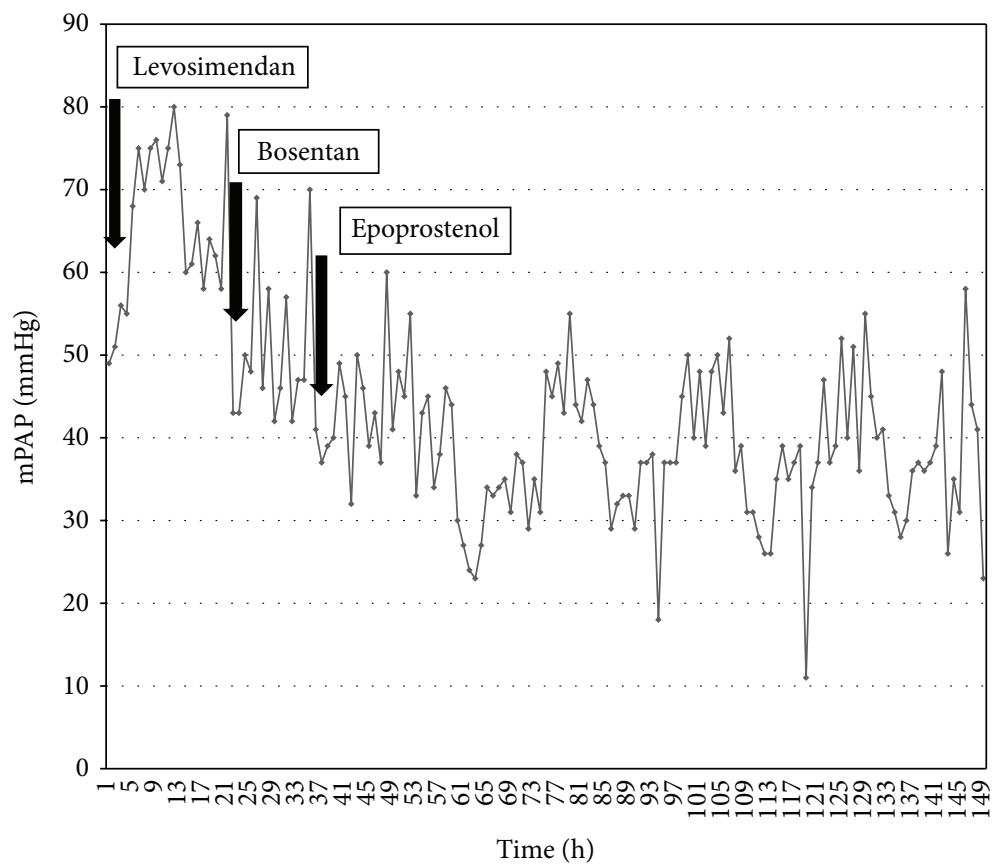

FIGURE 2: Original recording of invasively measured mean pulmonary artery pressures on ICU (days 1-5) and initiation of administration of levosimendan, bosentan, and epoprostenol.

the right parasternal border and a pronounced 2nd heart sound.

Invasive measurements and calculations at baseline in conscious sedation at room air during heart catheterization were mean pulmonary artery pressure (mPAP) $58 \mathrm{mmHg}$, pulmonary capillary wedge pressure (PCWP) $30 \mathrm{mmHg}$, transpulmonary pressure gradient (TPG) $28 \mathrm{mmHg}$, cardiac index (CI) $2.61 / \mathrm{min} / \mathrm{m}^{2}$, and pulmonary vascular resistance index (PVRI) $11 \mathrm{WU} \times \mathrm{m}^{2}$; there was no pressure gradient across the aortic valve. On pulmonary vasoreactivity testing
(100\% oxygen + nitric oxide $20 \mathrm{ppm})$, mPAP increased to $67 \mathrm{mmHg}$, PCWP increased to $35 \mathrm{mmHg}$, TPG increased to $31 \mathrm{mmHg}$, and CI increased to $3.11 / \mathrm{min} / \mathrm{m}^{2}$, while PVRI basically remained unchanged with $10 \mathrm{WU} \times \mathrm{m}^{2}$. A Swan Ganz catheter was inserted, the patient was put on diuretics (furosemide $1 \mathrm{mg} / \mathrm{kg} / \mathrm{d}$, spironolactone $1 \mathrm{mg} / \mathrm{kg} / \mathrm{d}$ ), and a course of levosimendan $(0.1 \mu \mathrm{g} / \mathrm{kg} / \mathrm{min}$ for 24 hours $)$ was administered. After levosimendan, PCWP constantly decreased to values around $25 \mathrm{mmHg}$ but $\mathrm{mPAP}$ increased up to $80 \mathrm{mmHg}$ while cardiac index remained stable (Figure 2). 


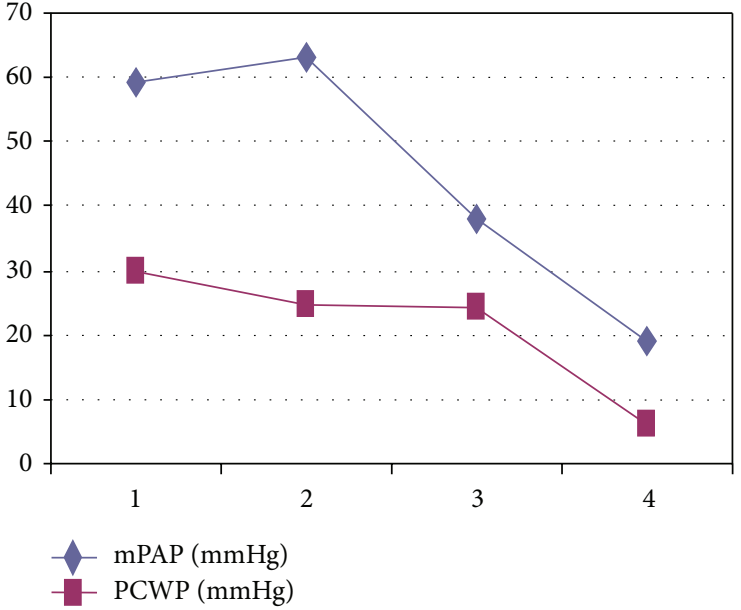

(a)

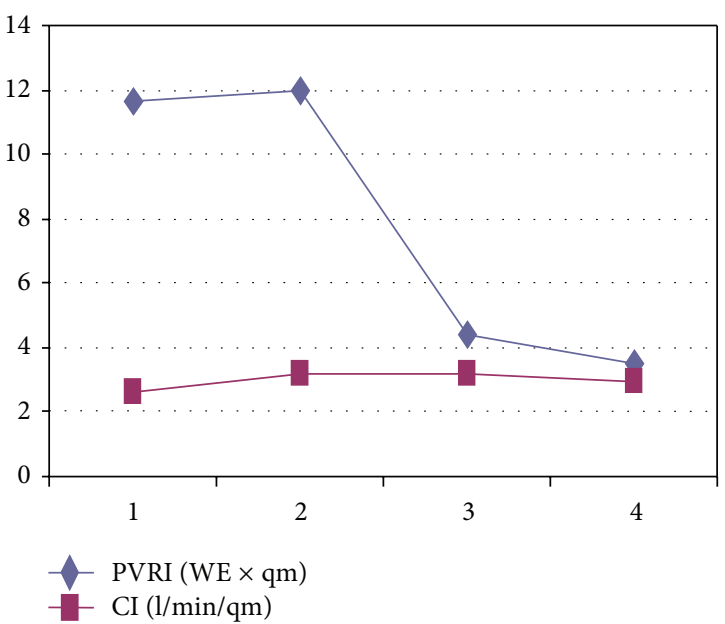

(b)

FIGURE 3: Hemodynamic measurements before and after heart transplantation. Mean pulmonary artery pressure (mPAP) pulmonary capillary wedge pressure (PCWP) (a). Pulmonary vascular resistance index (PVRI) and cardiac index (CI) (b). Time course before (1) and after levosimendan (2), with bosentan/epoprostenol (3) and after heart transplantation (4).

TABLE 1: Hemodynamic measurements and calculated values before and after heart transplantation: time course before (1) and after levosimendan (2), with bosentan/epoprostenol (3) and after heart transplantation (4).

\begin{tabular}{lccccc}
\hline & 1 & 2 & 3 & 4 & Units \\
\hline sPAP & 78 & 84 & 56 & 29 & $\mathrm{mmHg}$ \\
mPAP & 59 & 63 & 38 & 19 & $\mathrm{mmHg}$ \\
dPAP & 50 & 50 & 28 & 11 & $\mathrm{mmHg}$ \\
PVRI & 11.6 & 12 & 4.4 & 3.5 & $\mathrm{WU} \times \mathrm{m}^{2}$ \\
PCWP & 30 & 25 & 24 & 6 & $\mathrm{mmHg}$ \\
TPG & 29 & 39 & 14 & 13 & $\mathrm{mmHg}$ \\
sSAP & 89 & 99 & 94 & 73 & $\mathrm{mmHg}$ \\
mSAP & 65 & 72 & 67 & 59 & $\mathrm{mmHg}$ \\
dSAP & 73 & 60 & 53 & 50 & $\mathrm{mmHg}$ \\
SVRI & 21.8 & 16.8 & 19.7 & 17.9 & $\mathrm{WU} \times \mathrm{m}^{2}$ \\
CI & 2.6 & 3.2 & 3.2 & 3.7 & $\mathrm{~L} / \mathrm{min} / \mathrm{m}^{2}$ \\
\hline
\end{tabular}

Systolic, mean, and diastolic pulmonary artery pressure (sPAP, mPAP, and dPAP); pulmonary vascular resistance index (PVRI); pulmonary capillary wedge pressure (PCWP); transpulmonary pressure gradient (TPG); systolic, mean, and diastolic systemic artery pressure (sSAP, mSAP, and dSAP); systemic vascular resistance index (SVRI); cardiac index (CI).

The markedly elevated TPG of up to $55 \mathrm{mmHg}$ was taken for out-of-proportion pulmonary hypertension inadequate to the postcapillary component. Therefore, oral bosentan $125 \mathrm{mg} / \mathrm{d}$ and i.v. epoprostenol $2 \mathrm{ng} / \mathrm{kg} / \mathrm{min}$ were started. This led to a substantial decrease of pulmonary vascular constriction, demonstrated by a decrease of mPAP to $38 \pm$ $8 \mathrm{mmHG}$, without relevant changes in CI (values around $3.0 \mathrm{l} / \mathrm{min} / \mathrm{m}^{2}$ ) and PCWP (values of around $24 \mathrm{mmHG}$ ). TPG thus decreased to values of 16 to $22 \mathrm{mmHg}$. Calculated PVRI was between 4 and $5 \mathrm{WU} \times \mathrm{m}^{2}$ (Table 1, Figure 3 ).

The Swan Ganz catheter was removed 6 days later, and the patient was listed for heart transplantation. He remained stable on bosentan, epoprostenol, and diuretics until a donor heart became available. Heart transplantation was then successfully performed after 28 days on the waiting list. Perioperatively the patient received NO $20 \mathrm{ppm}$. Bosentan and epoprostenol were stopped on the first postoperative day and oral sildenafil $3 \times 10 \mathrm{mg} / \mathrm{d}$ was initiated. The patient was weaned from NO two days after transplantation. His perioperative course was completely uneventful with a cardiac index of $2.5-3.51 / \mathrm{min} / \mathrm{m}^{2}$, a PCWP of $12 \mathrm{mmHG}$, and $\mathrm{mPAP}$ of $30 \mathrm{mmHg}$ immediately after transplantation. Heart catheterization three weeks later revealed normal PCWP $(6 \mathrm{mmHg}), \mathrm{mPAP}(19 \mathrm{mmHg})$, PVRI $\left(3.5 \mathrm{WU} \times \mathrm{m}^{2}\right)$, and TPG (13 mmHg) (Table 1). Four weeks after heart transplantation, sildenafil was stopped and the patient was discharged home.

Gross examination of the explanted heart showed globular enlargement and an extensive endocardial fibroelastosis of the left ventricle with involvement of the aortic and mitral valves, the papillary muscles, and chordae tendineae (Figure 4).

\section{Discussion}

Pulmonary hypertension $(\mathrm{PH})$, secondary to structural or functional left heart disease in children, represents a delicate clinical condition where treatment options are often limited. The presence of endocardial fibroelastosis (Figure 4) in congenital aortic valve stenosis carries a poor prognosis; it is not correlated with the amount of aortic valve stenosis before or after intervention [2]. Reich et al. describe an incidence of $13.8 \%$ of EFE in long-term results of 269 patients after percutaneous balloon valvuloplasty [3]. It is thought that this fibroelastosis is a consequence of persistent pressure overload or decreased flow in the ventricle being present in early infancy and even in the fetus. Decreased diastolic function with preserved systolic function is present; therefore, 


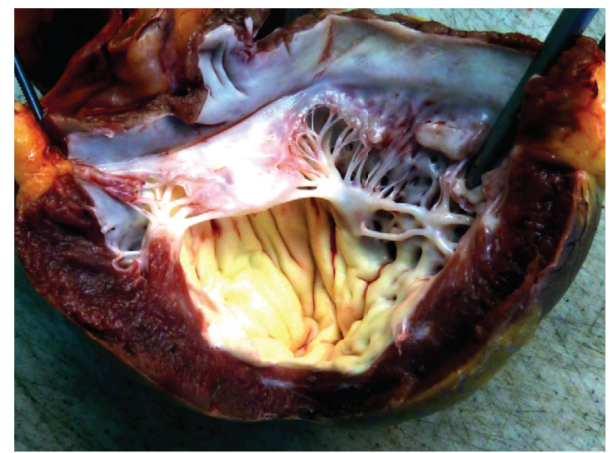

FIGURE 4: Pathologic specimen of the explanted heart. Endocardial fibroelastosis of the left ventricle affecting the papillary muscles with thickened and shortened chordae tendineae and the aortic and mitral valve (reprinted from [1] with permission from Elsevier).

diagnosis by means of echocardiography often is difficult. Left ventricular diastolic dysfunction leads to high filling pressures and enlargement of the left atrium. Pulmonary capillary wedge pressure rises, which leads to an increase in mPAP. This form of pulmonary hypertension is classified as pulmonary hypertension owing to left heart disease (group 2, Dana Point Classification) [4] characterized by an increased PCWP and a diastolic pulmonary artery pressure gradient of $\geq 10 \mathrm{mmHg}$. The TPG is calculated as the difference between the mean PA pressure and PCWP. By definition, it is flowindependent and thus may better reflect resistance to flow across the pulmonary bed. It is assumed that a TPG of around $15 \mathrm{mmHg}$ is acceptable for heart transplantation, although there is no accurate definition yet. We and others consider pulmonary hypertension to be inadequately high to left heart disease when the MPAP is severely elevated in the presence of moderately elevated PCWP or LVEDP $(\geq 22 \mathrm{mmHg})$ and a TPG of 18-20 mmHg [5]. These patients have a poor outcome after heart transplantation alone [6]; thus, a combined heartlung transplantation is considered to be the only surgical option.

Medical treatment of pulmonary hypertension by advanced therapies without treating the underlying left heart disease can lead to severe pulmonary congestion [7]. Therefore, it is mandatory to test vasoreactivity of the pulmonary artery bed prior to therapy. The reversibility of increased PVR or TPG under pharmacologic testing is supposed to indicate a decreased probability of right ventricular failure/death after transplantation [8]. It has been shown that, for example, in patients with mitral stenosis, surgical or interventional decompression of the left atrium with a concomitant rapid decrease in the LA and PCWP is followed by a marked decrease in PA pressure. Lower TPG eventually resulted in normalization of the pulmonary artery pressure [9].

What is remarkable in this case is the substantial and somewhat unexpected increase of pulmonary artery pressure after improvement of left ventricular restrictive kinetics by diuretics and levosimendan. At that point, we felt safe enough to initiate pulmonary vasodilative therapy in order to lower PVR.
The positive inotropic action of levosimendan is due to its binding to troponin $\mathrm{C}$ which facilitates the interaction between actin and myosin filaments without changes in intracellular $\mathrm{Ca}++$ ion concentrations $[10,11]$. Because of its calcium sensitizing mechanism levosimendan leads even to a shorter isovolumic relaxation time [12]. In addition, the drug produces peripheral, coronary [13], and pulmonary vasodilation by opening ATP-sensitive potassium channels [14]. These mechanisms lead to an improved myocardial contractility and a better diastolic function of both the left and the right heart without increasing myocardial oxygen consumption. Improved right heart function and a previously "hidden" precapillary pulmonary vasoconstriction might have increased PAP and PVRI. A decrease in PAP and PVRI [15] and in filling pressures of the right ventricle [16], like in this case by vasodilating agents, could result in an increased contractility and mechanical effectiveness of the right ventricle $[17,18]$.

After consultation of several centers with superb expertise, surgical options like resection of EFE and mitral valve plasty as well as extra corporal mechanical support by means of left ventricular assist device were omitted in our patient and heart transplantation was considered as the therapeutic strategy with most favorable prognostic outcome for this young boy.

Diuretics and levosimendan led to a substantial improvement of diastolic left heart function. Our own experience of beneficial effects of pulmonary vascular dilative medical therapy with bosentan in patients with heart failure with a normal ejection fraction with $\mathrm{PVH}$ and right ventricular failure [19] led us to consider the application of an endothelin1-receptor antagonist in this case. In addition a therapy with epoprostenol, of which beneficial effects on reversibility of pulmonary hypertension in congestive heart failure prior to cardiac transplantation are known, was started [8, 20-22].

The pursued stepwise increase of epoprostenol from the initial dose of $2 \mathrm{ng} / \mathrm{kg} / \mathrm{min}$ could not be carried out due to systemic hypotension ( $\mathrm{RR}<100 / 60 \mathrm{mmHg}$ ), most probably because of synergistic vasodilative effects of both drugs on the systemic vasculature. Therefore we consider bosentan as the main acting drug on the pulmonary vascular bed in this case.

\section{Conclusion}

Invasive monitoring of therapeutic effects on left heart function and pulmonary vasoreactivity is mandatory before deciding on heart or heart lung transplantation in patients with pulmonary hypertension owing to left heart disease.

\section{Conflict of Interests}

The authors declare that they have no conflict of interests.

\section{References}

[1] C. M. Steger, H. Antretter, and P. L. Moser, "Endocardial fibroelastosis of the heart," The Lancet, vol. 379, no. 9819, 932 pages, 2012. 
[2] J. D. Robinson, P. J. Del Nido, R. L. Geggel, A. R. Perez-Atayde, J. E. Lock, and A. J. Powell, "Left ventricular diastolic heart failure in teenagers who underwent balloon aortic valvuloplasty in early infancy," American Journal of Cardiology, vol. 106, no. 3, pp. 426-429, 2010.

[3] O. Reich, P. Tax, J. Marek et al., "Long term results of percutaneous balloon valvoplasty of congenital aortic stenosis: independent predictors of outcome," Heart, vol. 90, no. 1, pp. 70-76, 2004.

[4] G. Simonneau, I. M. Robbins, M. Beghetti et al., "Updated clinical classification of pulmonary hypertension," Journal of the American College of Cardiology, vol. 54, no. 1, supplement 1, pp. S43-S54, 2009.

[5] R. L. Benza and J. A. Tallaj, "Pulmonary hypertension out of proportion to left heart disease," Advances in Pulmonary Hypertension, vol. 5, no. 1, pp. 21-29, 2006.

[6] J. K. Kirklin, D. C. Naftel, J. W. Kirklin, E. H. Blackstone, C. White-Williams, and R. C. Bourge, "Pulmonary vascular resistance and the risk of heart transplantation," Journal of Heart Transplantation, vol. 7, no. 5, pp. 331-336, 1988.

[7] O. Nallet, O. Milleron, F. Monsel, B. Safar, I. Ghrissi, and J. Sergent, "Pulmonary hypertension and heart failure: the role of pulmonary vasculature," Annales de Cardiologie et d'Angeiologie, vol. 58, no. 5, pp. 304-309, 2009.

[8] M. Trautnitz, S. Pehlivanli, J. Behr et al., "Pharmacological testing of the reversibility of increased pulmonary vascular resistance before heart transplantation with prostaglandin I2 (prostacyclin)," Zeitschrift für Kardiologie, vol. 88, pp. 133-140, 1999 (German).

[9] S. M. Emani, E. A. Bacha, D. B. McElhinney et al., "Primary left ventricular rehabilitation is effective in maintaining twoventricle physiology in the borderline left heart," Journal of Thoracic and Cardiovascular Surgery, vol. 138, no. 6, pp. 12761282, 2009.

[10] H. Haikala, J. Kaivola, E. Nissinen, P. Wall, J. Levijoki, and I. B. Linden, "Cardiac troponin $\mathrm{C}$ as a target protein for a novel calcium sensitizing drug, levosimendan," Journal of Molecular and Cellular Cardiology, vol. 27, no. 9, pp. 1859-1866, 1995.

[11] F. Follath, "Newer treatments of decompensated heart failure: focus on levosimendan," Journal of Drug Design, Development and Therapy, vol. 3, pp. 73-78, 2009.

[12] H. Tachibana, H.-J. Cheng, T. Ukai et al., "Levosimendan improves LV systolic and diastolic performance at rest and during exercise after heart failure," American Journal of Physiology, vol. 288, no. 2, pp. H914-H922, 2005.

[13] H. Yokoshiki, Y. Katsube, M. Sunagawa, and N. Spereulkis, "The novel calcium sensitizer levosimendan activates the ATPsensitive $\mathrm{K}^{+}$-channel in rat ventricular cells," Journal of Pharmacology and Experimental Therapeutics, vol. 283, no. 1, pp. 375383, 1997.

[14] S. Rehberg, C. Ertmer, H. Van Aken et al., "Role of levosimendan in intensive care treatment of myocardial insufficiency," Anaesthesist, vol. 56, no. 1, pp. 30-43, 2007.

[15] M. S. Nieminen, J. Akkila, G. Hasenfuss et al., "Hemodynamic and neurohumoral effects of continuous infusion of levosimendan in patients with congestive heart failure," Journal of the American College of Cardiology, vol. 36, no. 6, pp. 1903-1912, 2000.

[16] M. T. Slawsky, W. S. Colucci, S. S. Gottlieb et al., "Acute hemodynamic and clinical effects of levosimendan in patients with severe heart failure," Circulation, vol. 102, no. 18, pp. 22222227, 2000.
[17] H. A. Leather, K. Ver Eycken, P. Segers, P. Herijgers, E. Vandermeersch, and P. F. Wouters, "Effects of levosimendan on right ventricular function and ventriculovascular coupling in open chest pigs," Critical Care Medicine, vol. 31, no. 9, pp. 2339-2343, 2003.

[18] H. Ukkonen, M. Saraste, J. Akkila et al., "Myocardial efficiency during levosimendan infusion in congestive heart failure," Clinical Pharmacology and Therapeutics, vol. 68, no. 5, pp. 522531, 2000.

[19] W. Grander, P. Eller, J. Gänzer, H. Tilg, and R. Geiger, “Bosentan treatment in chronic pulmonary venous hypertension with significant right heart dysfunction," Current Medical Research and Opinion, vol. 23, no. 2, pp. S71-S76, 2007.

[20] S. Murali, B. F. Uretsky, P. S. Reddy, T. R. Tokarczyk, and A. R. Betschart, "Reversibility of pulmonary hypertension in congestive heart failure patients evaluated for cardiac transplantation: comparative effects of various pharmacologic agents," American Heart Journal, vol. 122, no. 5, pp. 1375-1381, 1991.

[21] A. E. Lammers, A. A. Hislop, Y. Flynn, and S. G. Haworth, "Epoprostenol treatment in children with severe pulmonary hypertension," Heart, vol. 93, no. 6, pp. 739-743, 2007.

[22] F. Perez-Villa, A. Cuppoletti, V. Rossel, I. Vallejos, and E. Roig, "Initial experience with bosentan therapy in patients considered ineligible for heart transplantation because of severe pulmonary hypertension," Clinical Transplantation, vol. 20, no. 2, pp. 239244, 2006. 


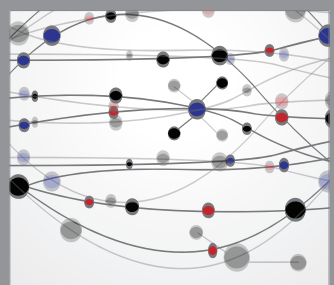

The Scientific World Journal
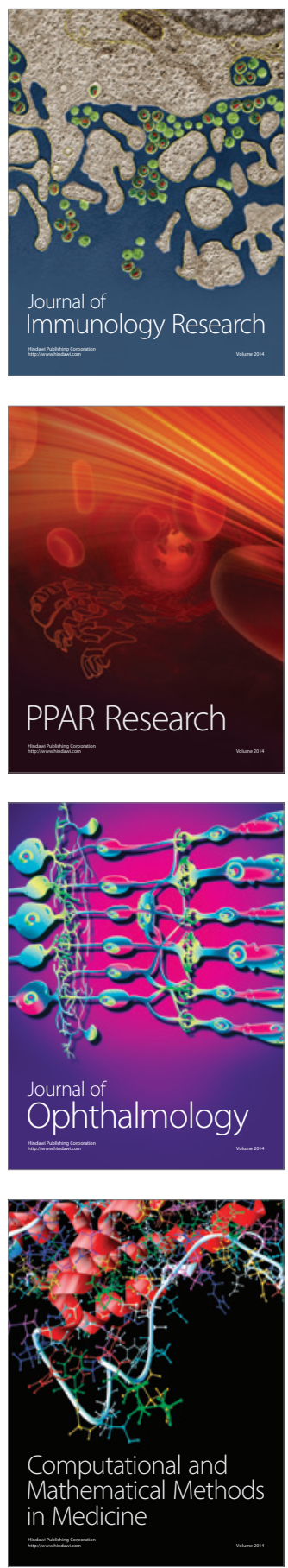

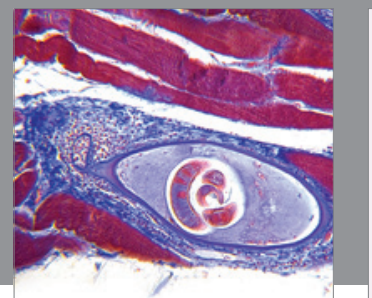

Gastroenterology

Research and Practice
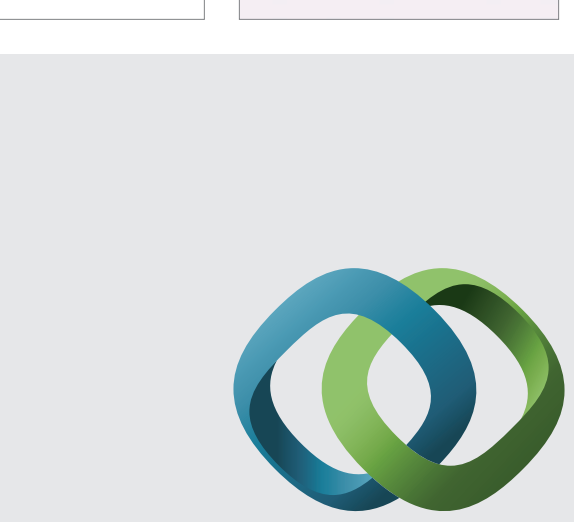

\section{Hindawi}

Submit your manuscripts at

http://www.hindawi.com
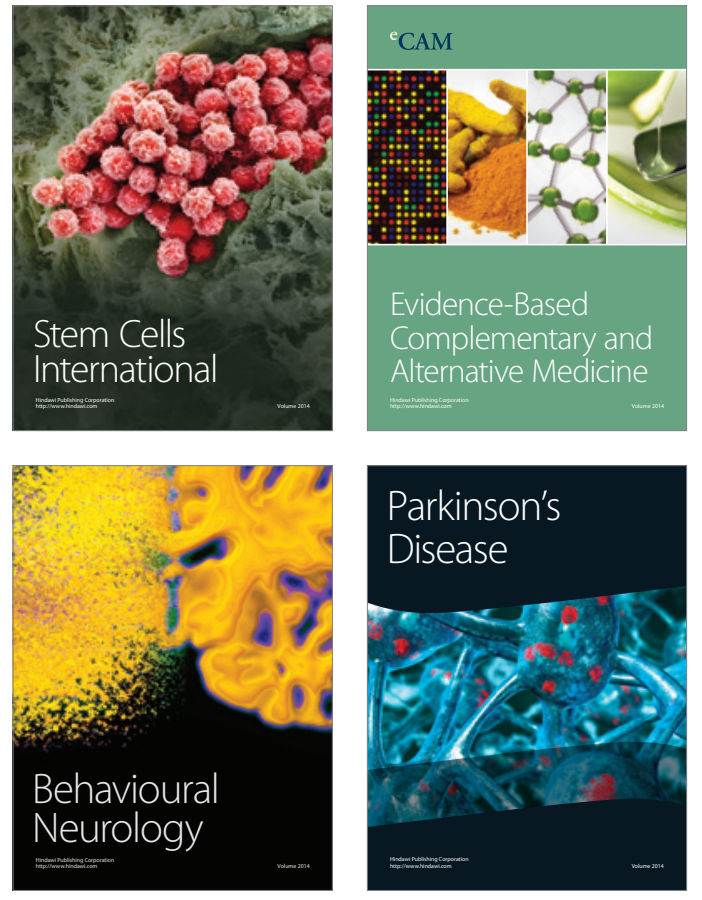
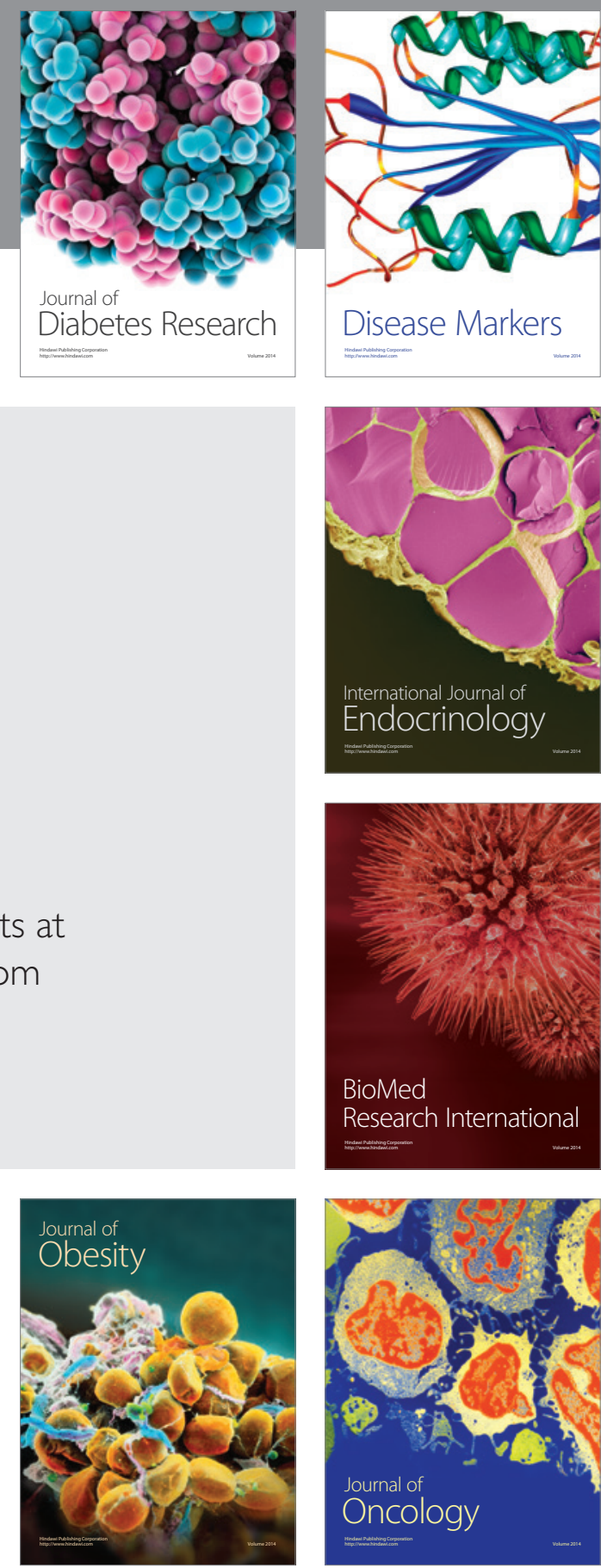

Disease Markers
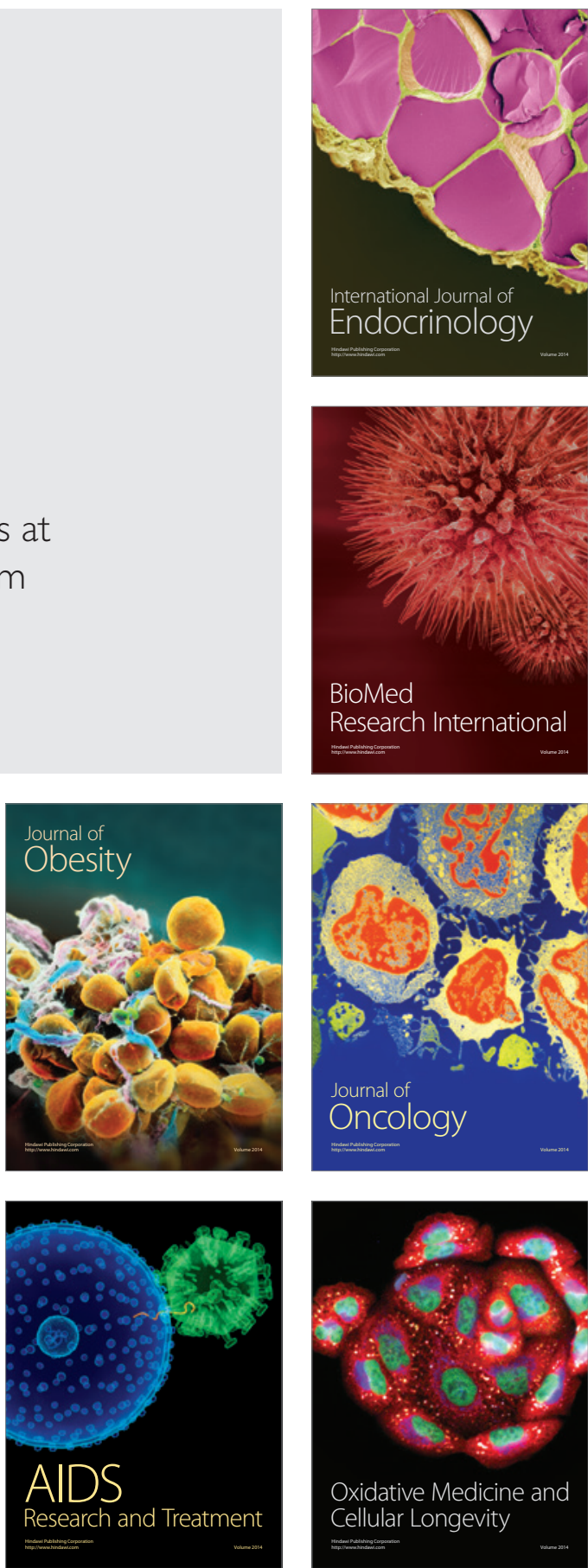